\title{
The Influence of Melt Convection on Dendritic Spacing of Downward Unsteady-State Directionally Solidified Sn-Pb Alloys
}

\author{
José Eduardo Spinellia, Otávio Fernandes Lima Rocha ${ }^{\mathrm{b}}$,Amauri Garcia ${ }^{\mathrm{a}}$ * \\ ${ }^{a}$ Department of Materials Engineering State University of Campinas, UNICAMP, \\ P.O. Box 6122, 13083-970 Campinas - SP, Brazil \\ ${ }^{\mathrm{b}}$ Federal Center of Technological Education - CEFET, Belém - PA, Brazil
}

Received: December 2, 2004; Revised: August 8, 2005

\begin{abstract}
Microstructures are the strategic link between materials processing and materials behavior. A dendritic structure is the most frequently observed pattern of solidified alloys. The microstructural scales of dendrites, such as primary and secondary arm spacings, control the segregation profiles and the formation of secondary phases within interdendritic regions, determine the properties of cast structures. In this work, the influence of thermosolutal convection on dendrite arm spacings is experimentally examined in the downward vertical unsteadystate directional solidification of $\mathrm{Sn}-\mathrm{Pb}$ hypoeutectic alloys. The experimental observations are compared not only with the main predictive theoretical models for dendritic spacings but also with experimental results obtained for $\mathrm{Sn}-\mathrm{Pb}$ alloys solidified vertically upwards. Primary dendritic arm spacings have been affected by the direction of growth, decreasing in conditions of downward vertical solidification when compared with those grown vertically upwards. Further, the unsteady-state $\lambda_{1}$ predictive models did not generate the experimental observations.
\end{abstract}

Keywords: downward unidirectional solidification, dendritic spacings, dendritic growth models, $\mathrm{Sn}-\mathrm{Pb}$ alloys

\section{Introduction}

The fundamental understanding of the relationship between solidification variables and the resulting structure is essential for the development of improved methods for quality castings. Alloy solidification involves heat, fluid flow and the transport of solute, which influence the development of both the macrostructure and the microstructure. The prediction of these structures is of great interest for the evaluation and design of mechanical properties of castings.

Several theoretical models have been proposed in the literature to describe the dependence of primary and secondary dendrite arm spacings on solidification variables such as initial alloy composition, growth rate and thermal gradient ${ }^{1-8}$. Although convection effects strongly influence on the development of solidification microstructure, the main theoretical dendritic models from the literature are based on purely diffusive transport mechanisms. In addition, recent articles on cellular ${ }^{9,10}$ and primary dendritic ${ }^{11}$ growth under unsteady-state solidification conditions have shown that the predictive theoretical models existing in the literature did not generate the experimental observations.

Only a few studies have reported influences of interdendritic convection and direction of growth on dendrite arm spacings ${ }^{12-15}$. Burden and Hunt ${ }^{13}$ have carried out solidification experiments with the ammonium chloride/water system in order to investigate the effect of solute flow and direction of growth on primary dendrite arm spacings. In the case of downward growth, the lighter water-rich formed interdendritic liquid tends to flow upwards and fill the interdendritic space. In the upward growth the water-rich melt tends to flow into the bulk liquid. They have reported that primary spacings for downward growth were of an order of magnitude smaller than those observed for upward solidification. Hui et al. have reported a decrease of the mean primary dendritic spacing and a more disordered dendritic array caused by interdendritic convection during directional solidification of $\mathrm{Pb}-\mathrm{Sb}$ alloys ${ }^{12}$.
When the solute is denser than the solvent, a denser solute-enriched melt can be induced in the mushy zone and ahead of the growth interface. Under these conditions and considering upward vertical solidification (melt on top and solid below), it is expected that no natural convection occurs, since both the temperature and compositional gradients have a stabilizing effect on the density stratification. On the other hand, if a melt is cooled from the top, the fluid layer may become thermally unstable, and, hence, a thermal-buoyancy-driven flow occurs. Additionally, if the system has a denser interdendritic melt during downward solidification, the configuration leads to a situation where both thermal and compositional fields are unstable, and convective currents take place.

The main purpose of this article is to experimentally examine the influence of thermosolutal convection on dendrite arm spacings during the downward vertical solidification of hypoeutectic $\mathrm{Sn}-\mathrm{Pb}$ alloys, to discuss the application of the main primary and secondary theoretical dendrite spacing models in the presence of convection during solidification and, at last, to analyze the dendritic growth for both upward and downward unsteady-state solidification systems.

\section{Dendritic Growth Models}

Among the theoretical models existing in the literature only those proposed by Hunt and $\mathrm{Lu}^{1}$ for primary spacings and BouchardKirkaldy $^{2}$ for primary and secondary spacings assume solidification in unsteady-state heat flow conditions. Hunt ${ }^{3}$, Kurz and Fisher ${ }^{4,5}$, and Trivedi $^{6}$ have derived primary spacing formulae, which apply for steady-state conditions. The theoretical models for determination of dendritic spacings proposed by these authors are shown in Equations 1 to 8:

$$
\lambda_{1}=2.83\left[\Gamma \mathrm{m}_{\mathrm{L}} \mathrm{C}_{0}\left(1-\mathrm{k}_{0}\right) \mathrm{D}\right]^{1 / 4} \mathrm{G}_{\mathrm{L}}^{-1 / 2} \mathrm{~V}_{\mathrm{L}}{ }^{-1 / 4}
$$

(Hunt, cellular/dendritic) 
$\lambda_{1}=4.3\left(\frac{\Gamma \Delta \mathrm{TD}}{k_{0}}\right)^{1 / 4} \mathrm{G}_{\mathrm{L}}^{-1 / 2} \mathrm{~V}_{\mathrm{L}}^{-1 / 4}$

(Kurz and Fisher, cellular/dendritic)

$\lambda_{1}=2.83\left[\mathrm{LCm}_{\mathrm{L}} \mathrm{C}_{0}\left(1-\mathrm{k}_{0}\right) \mathrm{D}\right]^{1 / 4} \mathrm{GL}^{-1 / 2} \mathrm{~V}_{\mathrm{L}^{-1 / 4}}$

(Trivedi, dendritic)

$\lambda_{1}^{\prime}=0.07798 \mathrm{~V}^{{ }^{(\mathrm{a}-0.75)}}\left(\mathrm{V}^{\prime}-\mathrm{G}^{\prime}\right)^{0,75} \mathrm{G}^{\prime}-0.6028$

(Hunt-Lu, dendritic)

where:

$$
\begin{aligned}
& \mathrm{a}=-1.131-0.1555 \log _{10}\left(\mathrm{G}^{\prime}\right)-0.007589\left[\log _{10}\left(\mathrm{G}^{\prime}\right)\right]^{2} \\
& \lambda_{1}^{\prime}=\frac{\lambda_{1} \Delta \mathrm{T}}{\Gamma \mathrm{k}_{0}}, \mathrm{G}^{\prime}=\frac{\mathrm{G}_{\mathrm{L}} \Gamma \mathrm{k}_{0}}{\Delta \mathrm{T}^{2}} \text { and } \mathrm{V}^{\prime}=\frac{\mathrm{V}_{\mathrm{L}} \Gamma \mathrm{k}_{0}}{\mathrm{D} \Delta \mathrm{T}} \\
& \lambda_{1}=\mathrm{a}_{1}\left(\frac{16 \mathrm{C}_{0}^{1 / 2} \mathrm{G}_{0} \varepsilon \Gamma \mathrm{D}}{\left.\left(1-k_{0}\right) \mathrm{m}_{\mathrm{L}} \mathrm{G}_{\mathrm{L}} \mathrm{V}_{\mathrm{L}}\right)}\right)^{1 / 2}
\end{aligned}
$$

(Bouchard-Kirkaldy, primary dendritic)

where $\lambda_{1}$ is the primary dendritic spacing, $\Gamma$ is the Gibbs-Thomson coefficient, $\mathrm{m}_{\mathrm{L}}$ is the liquidus line slope, $\mathrm{k}_{0}$ the solute partition coefficient, $\mathrm{C}_{0}$ is the alloy composition, $\mathrm{D}$ is the liquid solute diffusivity, $\Delta \mathrm{T}$ is the difference between the liquidus and solidus equilibrium temperature, $\mathrm{V}_{\mathrm{L}}$ is the dendrite tip growth rate, $\mathrm{G}_{\mathrm{L}}$ is the temperature gradient in front of the liquidus isotherm, $\mathrm{G}_{0} \varepsilon$ is a characteristic parameter $\approx 600 \times 6 \mathrm{~K} \mathrm{~cm}^{-12}$ and $\mathrm{a}_{1}$ is the primary dendrite-calibrating factor.

Since the spacings proposed by Hunt and $\mathrm{Lu}$ (Equations 4-6) refer to the radius rather than to the more commonly measured diameter and they are minimum spacings, the values need to be multiplied by 2 to 4 for comparison with measured spacings. These authors have also pointed out that problems might expect to occur with the correlation of their theoretical predictions and experiment when extensive convection currents are present.

For secondary dendrite spacings, Bouchard and Kirkaldy ${ }^{2}$ have derived an expression, which is very similar to the Mullins, and Sekerka temperature gradient independent marginal wavelength formula, which is given by:

$$
\lambda_{2}=2 \pi \mathrm{a}_{2}\left(\frac{4 \Gamma}{\mathrm{C}_{0}\left(1-\mathrm{k}_{0}\right)^{2} T_{\mathrm{F}}}\left(\frac{\mathrm{D}}{\mathrm{V}_{\mathrm{L}}}\right)^{2}\right)^{\frac{1}{3}}
$$

where $\mathrm{a}_{2}$ is the secondary dendrite-calibrating factor, which depends on the alloy composition and $\mathrm{T}_{\mathrm{F}}$ is the fusion temperature of the solvent.

Feurer and Wunderlin ${ }^{7}$ and Kirkwood ${ }^{8}$ have derived secondary spacings formulas as a function of local solidification time, which differ only by a small factor in the numerical constant, and can be expressed as:

$$
\lambda_{2}=\mathrm{K}\left(\mathrm{Mt}_{\mathrm{SL}}\right)^{1 / 3}[\mathrm{~m}]
$$

where:

$$
\mathrm{M}=-\frac{\Gamma \mathrm{D}}{\left(1-\mathrm{k}_{0}\right) \mathrm{m}_{\mathrm{L}}\left(\mathrm{C}_{\mathrm{E}}-\mathrm{C}_{0}\right)} \ln \left(\frac{\mathrm{C}_{\mathrm{E}}}{\mathrm{C}_{0}}\right)\left[\mathrm{m}^{3} / \mathrm{s}\right]
$$

$\mathrm{K}=5.5$ (Feurer and Wunderlin) or $\mathrm{K}=5.0$ (Kirkwood) and $\mathrm{C}_{\mathrm{E}}$ is eutectic composition.

Rocha et al. ${ }^{16}$ have observed that a -0.55 power law can characterize the experimental variation of primary spacings with cooling rate along the unsteady-state solidification of hypoeutectic $\mathrm{Sn}-\mathrm{Pb}$ and $\mathrm{Al}-\mathrm{Cu}$ alloys, and that $\mathrm{a}-2 / 3$ power law represents the experimental variation of secondary spacings with tip growth rate. Peres et al. ${ }^{17}$ have recently reported similar observations concerning the directional solidification of Al-Si alloys. These experimental laws are shown in Equations 11 and 12:

$$
\lambda_{1}=\mathrm{A}\left(\dot{\mathrm{T}}_{\mathrm{L}}\right)^{-0.55}
$$

where $\lambda_{1}[\mu \mathrm{m}] ; \dot{\mathrm{T}}_{\mathrm{L}}[\mathrm{K} / \mathrm{s}] ; \mathrm{A}=80.5,44$ and 25 for Sn-5wt.\% $\mathrm{Pb}$, $\mathrm{Sn}-15 \mathrm{wt} . \% \mathrm{~Pb}$ and $\mathrm{Sn}-30 \mathrm{wt} . \% \mathrm{~Pb}$, respectively; $\mathrm{A}=250$ for $\mathrm{Al}-\mathrm{Cu}$ hypoeutectic alloys, and $\mathrm{A}=220$ for $\mathrm{Al}-\mathrm{Si}$ hypoeutectic alloys.

$$
\lambda_{2}=\mathrm{B}\left(\mathrm{V}_{\mathrm{L}}\right)^{-2 / 3}
$$

where $\lambda_{2}[\mu \mathrm{m}] ; \mathrm{V}_{\mathrm{L}}(\mathrm{mm} / \mathrm{s}) ; \mathrm{B}=25,11$ and 7 for $\mathrm{Sn}-5 \mathrm{wt} . \% \mathrm{~Pb}, \mathrm{Sn}-$ $15 \mathrm{wt} . \% \mathrm{~Pb}$ and $\mathrm{Sn}-30 \mathrm{wt} . \% \mathrm{~Pb}$, respectively; $\mathrm{B}=31,24$ and 22 for $\mathrm{Al}-5 \mathrm{wt} . \% \mathrm{Cu}, \mathrm{Al}-8 \mathrm{wt} . \% \mathrm{Cu}$ and $\mathrm{Al}-10 \mathrm{wt} . \% \mathrm{Cu}$, respectively; and $\mathrm{B}=32,26$ and 22 for $\mathrm{Al} 3$ and 5wt. $\% \mathrm{Si}, \mathrm{Al}-7 \mathrm{wt} . \% \mathrm{Si}$ and $\mathrm{Al}-9 \mathrm{wt} . \% \mathrm{Si}$, respectively.

\section{Experimental Procedure}

The casting assembly used in solidification experiments is shown in Figure 1. It was designed in such way that the heat was extracted only through the water-cooled system at the top, promoting vertical downward directional solidification. A stainless steel split mold was used having an internal diameter of $57 \mathrm{~mm}$, height $150 \mathrm{~mm}$ and wall thickness $10 \mathrm{~mm}$. The lateral inner mold surface was covered with a layer of insulating alumina to minimize radial heat losses. The upper part of the split mold was closed with a water-cooling chamber made of stainless steel, with a wall thickness of $3 \mathrm{~mm}$.

The alloys were melted in situ and the lateral electric heaters had their power controlled in order to permit a desired melt superheat to be achieved. To begin solidification, the electric heaters were disconnected and at the same time the water flow was initiated.

The experiments were performed with $\mathrm{Sn}-\mathrm{Pb}$ alloys $(5,15$ and $20 \mathrm{wt} . \% \mathrm{~Pb}$ ) with melt superheats of $7{ }^{\circ} \mathrm{C}$ above the liquidus temperature, and under a thermal contact condition at the metal $/ \mathrm{mold}$ interface corresponding to the heat-extracting surface being polished. The employed thermophysical properties of these alloys are those reported in a previous article ${ }^{11}$.

Temperatures in the casting were monitored during solidification via the output of a bank of fine type $J$ thermocouples, sheathed in $1.6 \mathrm{~mm}$ O.D. stainless steel protection tubes, and accurately positioned in seven different positions with regard to the heat extracting surface.

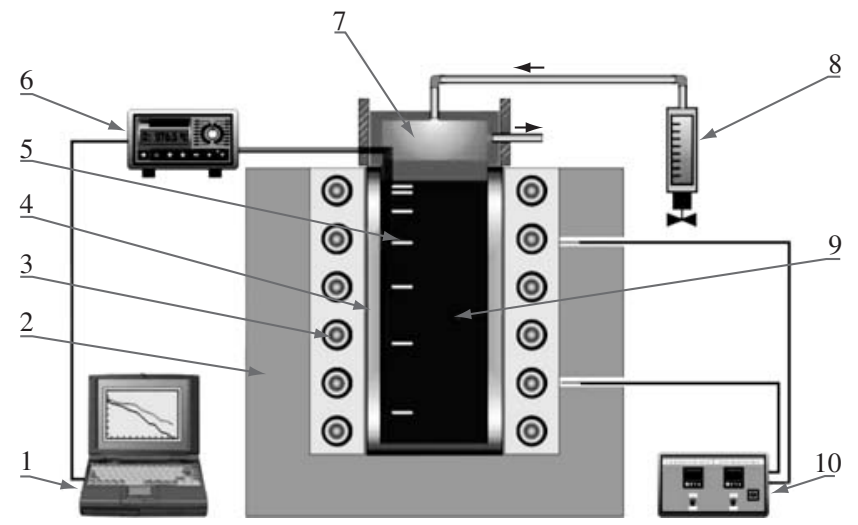

Figure 1. Schematic representation of the experimental setup: 1) data storage computer; 2) insulating ceramic shielding; 3) electric heaters; 4) stainless steel mold; 5) thermocouples; 6) data logger; 7) water-cooled chamber; 8) rotameter; 9) casting; and 10) temperature controller. 
Longitudinal and transverse sections (perpendicular to the growth direction) from the directionally solidified specimens at 18 different positions along the ingot length were electropolished and etched with an acid solution $(50 \mathrm{~mL}$ glycerin, $35 \mathrm{~mL}$ acetic acid and $15 \mathrm{~mL}$ of $\mathrm{HNO}_{3}, 38$ to $40{ }^{\circ} \mathrm{C}$ ) for microscopy examination. Image processing systems Neophot 32 (Carl Zeiss, Esslingen, Germany) and Leica Quantimet 500 MC (Leica Imaging Systems Ltd, Cambridge, England) were used to measure dendrite spacings. The methods used for measurement of the dendrite arm spacings were those previously described in the literature ${ }^{11,18}$

\section{Results and Discussions}

The thermocouples readings were used to generate a plot of position from the metal/mold interface as a function of time corresponding to the liquidus front passing by each thermocouple. A curve fitting technique on these experimental points has generated a power function of position as a function of time. The derivative of this function with respect to time has yielded values for tip growth rate. Moreover, the data acquisition system employed permits accurate determination of the slope of the experimental cooling curves. Hence, the tip cooling rate was determined by considering the thermal data recorded immediately after the passing of the liquidus front by each thermocouple.

In Figure 2a experimental average secondary dendritic spacings along with the standard variation, are presented as a function of tip growth rate. It can be seen that a same power law can represent the variation of secondary spacings with tip growth rate for the 5 and $15 \mathrm{wt} . \% \mathrm{~Pb}$ alloys. When comparing the mean values of $\lambda_{2}$ obtained in the present investigation with those from the upward vertical experiments ${ }^{9-11}$, a tendency of reduction of secondary dendritic arms can be observed for the $\mathrm{Sn}-5 \mathrm{wt} \% \mathrm{~Pb}$ alloy solidified downwards. However, the experimental values for the $\mathrm{Sn}-15 \mathrm{wt} . \% \mathrm{~Pb}$ are quite similar in both cases (upwards and downwards).

In Figure $2 \mathrm{~b}$ experimental average primary dendritic spacings along with the standard variation, are presented as a function of tip cooling rate. Points are experimental results and the line represents an empirical power function fit with the experimental points. It can be seen that, for the downward solidification, the same power law represents the variation of primary spacings with tip cooling rate for the 5 and $15 \mathrm{wt} . \% \mathrm{~Pb}$ alloys. Figure $2 \mathrm{a}$ shows also a comparison with the experimental laws obtained from the vertical upward directional solidification of these two alloys ${ }^{11}$. As can be seen, for a same cooling rate, the primary spacing is reduced (about 2 to 3 times) for conditions of downward vertical solidification. The interdendritic fluid flow has a different effect in the two cases, as shown by the schematic representation presented in Figure 3. In the case of upward vertical solidification (Figure 3a) the solutal profile in the mushy zone and in the overlying

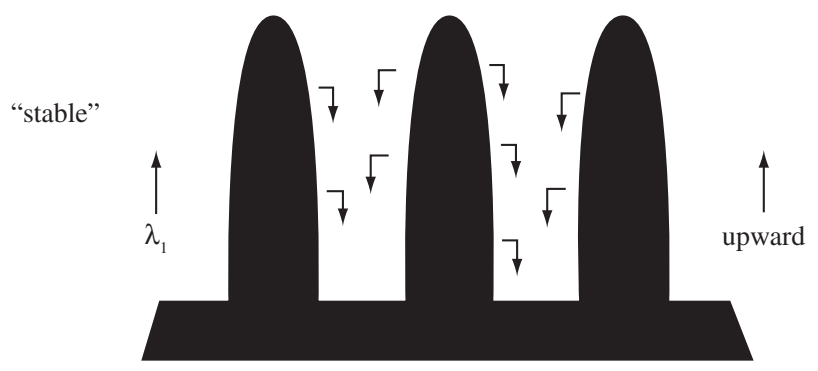

a) The heavier solute enriched melt fill the interdendritic space

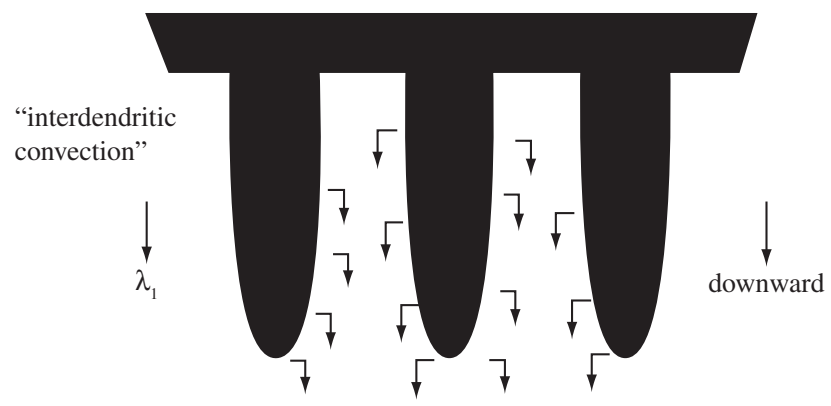

b) The heavier solute enriched melt tends to flow into the bulk liquid

Figure 3. Schematic representation of solute flow between primary dendritic arms growing, a) upwards; and b) downwards.

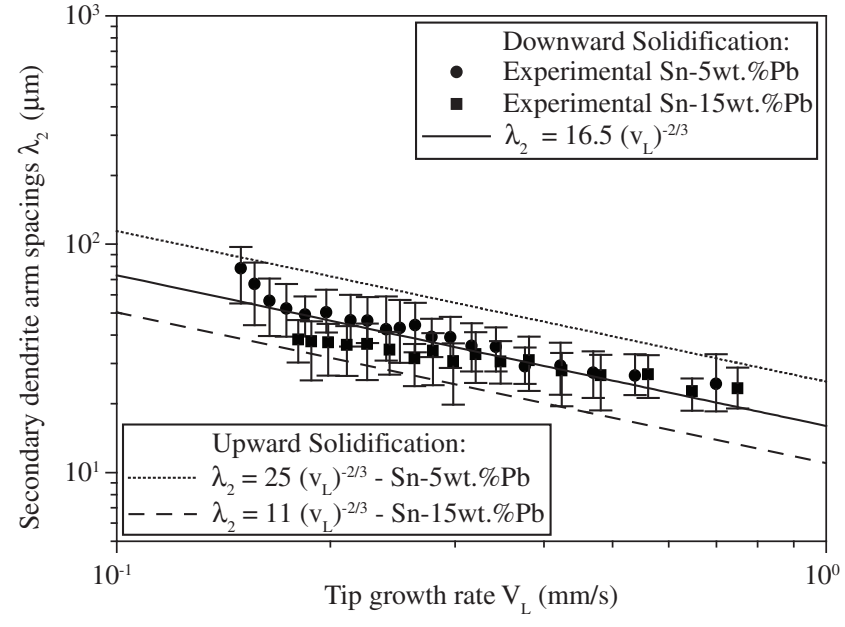

(a)

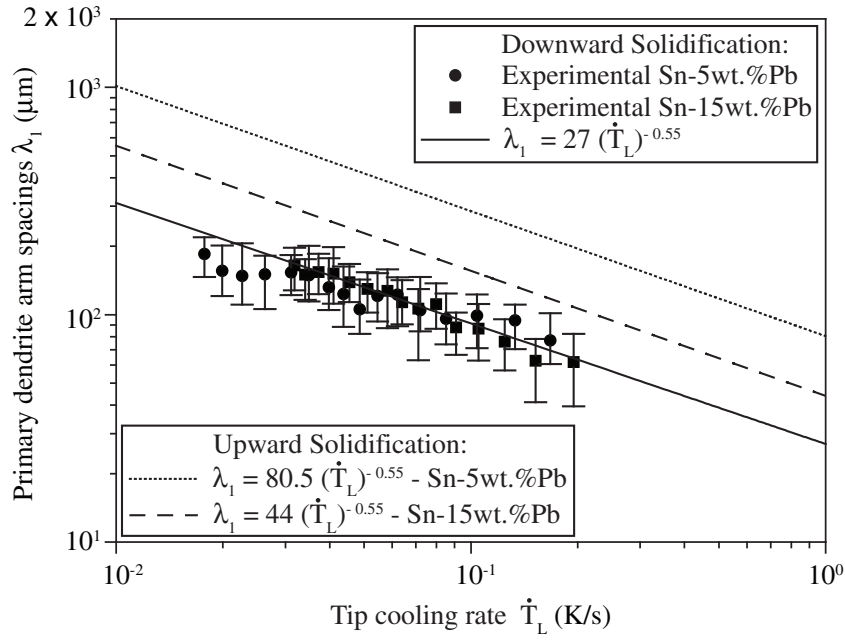

(b)

Figure 2. a) Secondary dendrite arm spacing as a function of tip growth rate; and b) Primary dendrite arm spacing as a function of tip cooling rate. 
melt ahead of the dendritic array is expected to be stable because solute enrichment causes an increase in melt density. In the case of downward growth (Figure $3 b$ ) the heavier liquid formed in the interdendritic region and at the tip tends to flow downward into the bulk liquid. As suggested by Burden and Hunt ${ }^{13}$, the former situation aids the radial transport of material and leads to a larger spacing, and the latter case aids solute rejection and the need for lateral segregation, thus reducing the dendrite spacing. The present experimental observations concerning the reduction in $\lambda_{1}$ are in agreement with the results obtained by Hui et al. ${ }^{12}$ during directional solidification of $\mathrm{Pb}-\mathrm{Sb}$ alloys, and also agree with results from low-gravity experiments in $\mathrm{Al}-\mathrm{Cu}$ samples grown in a convection free environment ${ }^{14}$. In the latter situation primary spacings were 2 to 4 times larger than those observed in similar samples grown on earth in the presence of natural convection.

Figure 4 shows comparisons between the present experimental results of primary spacings with theoretical predictions furnished by unsteady-state predictive models. They are the Hunt-Lu's model (HL) represented by Equations 4-6, and Bouchard-Kirkaldy's model (BK),

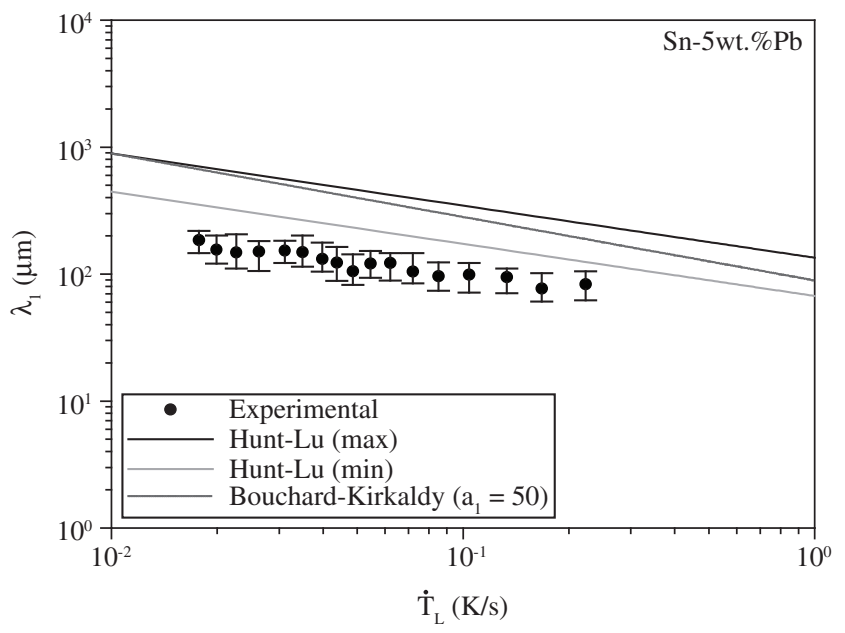

(a)

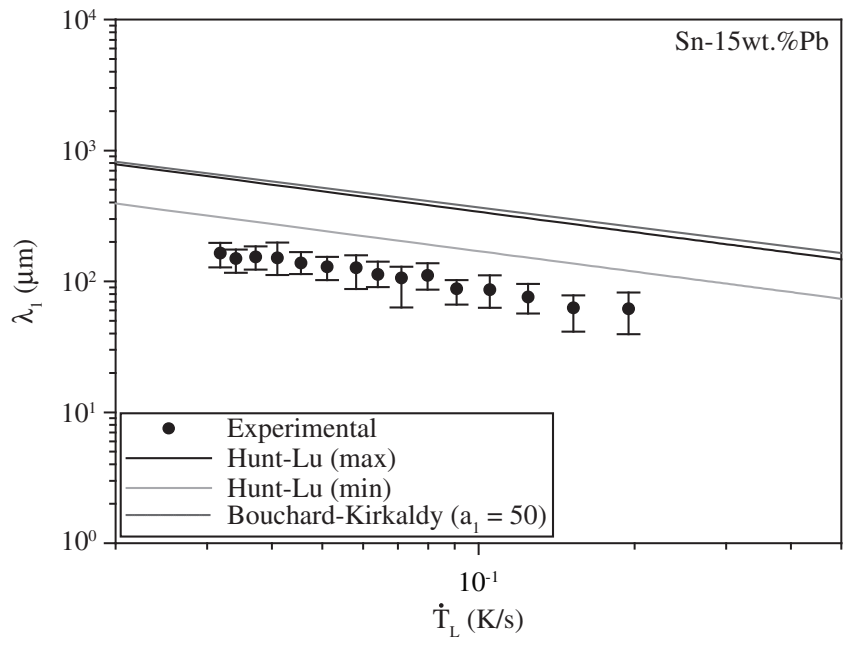

(b) given by Equation 7 with a calibrating factor $\mathrm{a}_{1}$ of 50 for $\mathrm{Sn}-\mathrm{Pb}$ alloys, as suggested by these authors ${ }^{2}$. It can be seen that, considering Sn-5, 15 and $20 \mathrm{wt} . \% \mathrm{~Pb}$ alloys downward solidified (Figure $4 \mathrm{a}, 4 \mathrm{~b}$ and $4 \mathrm{c}$, respectively); both models overestimate the primary spacings. In addition, in Figure 4d a comparison between the results of primary spacing concerning upward unsteady-state solidification conditions and the same theoretical models is presented. Similarly, the theoretical predictions overestimate the experimental results.

When analyzing the theoretical predictions furnished by steadystate predictive models existing in the literature performed against experimental results of unsteady downward solidification (Figure 5a, 5b and 5c), a good agreement between Hunt's model and the experimental results can be observed for any composition examined (it is convenient to recall that this model also considers only diffusive solutal transport). Nevertheless, Trivedi and Kurz-Fisher's models overestimate the primary spacings. On the contrary, it can be seen that all models overestimate the primary spacings during upward unsteady-state directional solidification of an Sn-15wt.\%Pb alloy (Figure 5d).

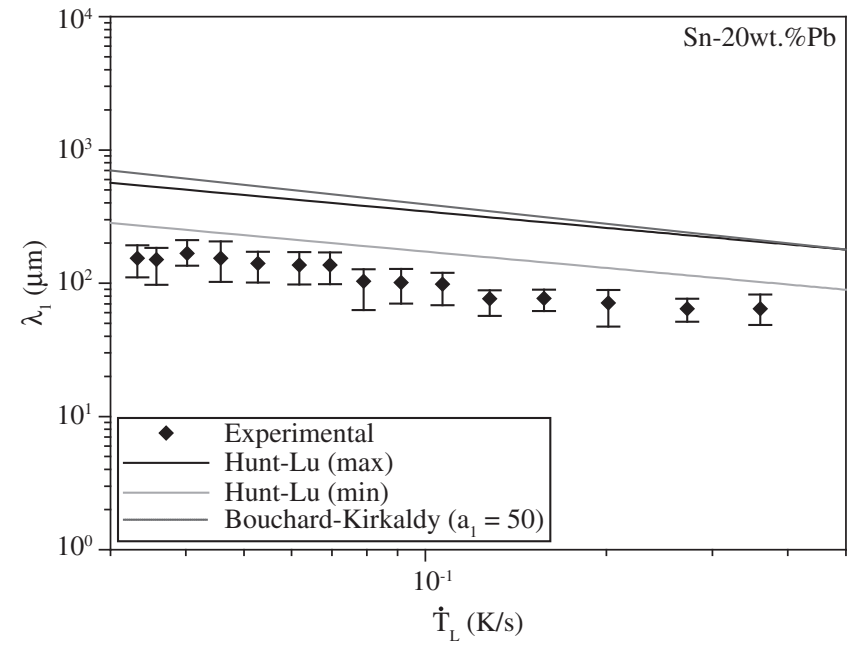

(c)

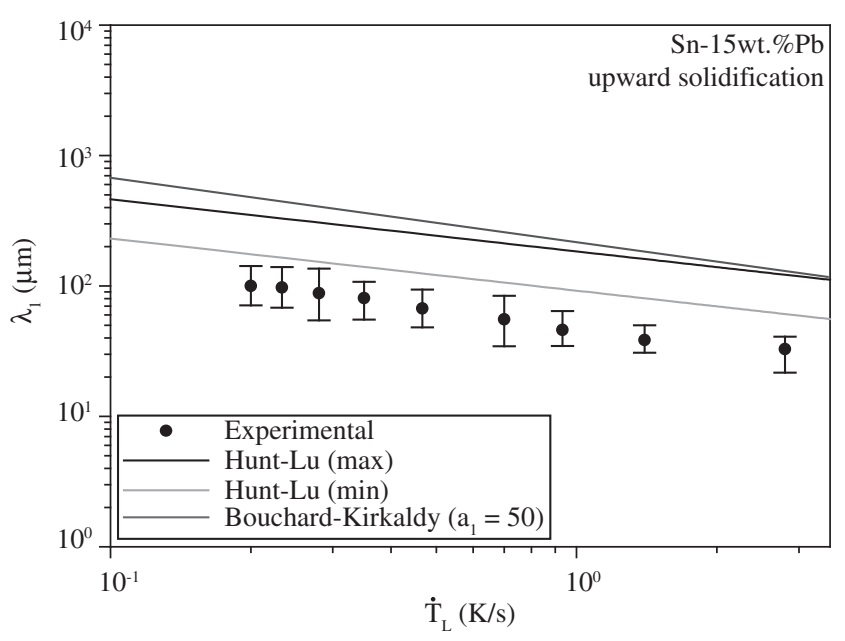

(d)

Figure 4. Comparison of experimental and theoretical primary dendrite arm spacing as a function of tip cooling rate for a) $\mathrm{Sn}-5 \mathrm{wt} . \% \mathrm{~Pb}$; b) $\mathrm{Sn}-15 \mathrm{wt} . \% \mathrm{~Pb}$; c) $\mathrm{Sn}-20 \mathrm{wt} . \% \mathrm{~Pb}$ alloys in downward unsteady-state directional solidification; and d) $\mathrm{Sn}-15 \% \mathrm{~Pb}$ upward directionally solidified. 


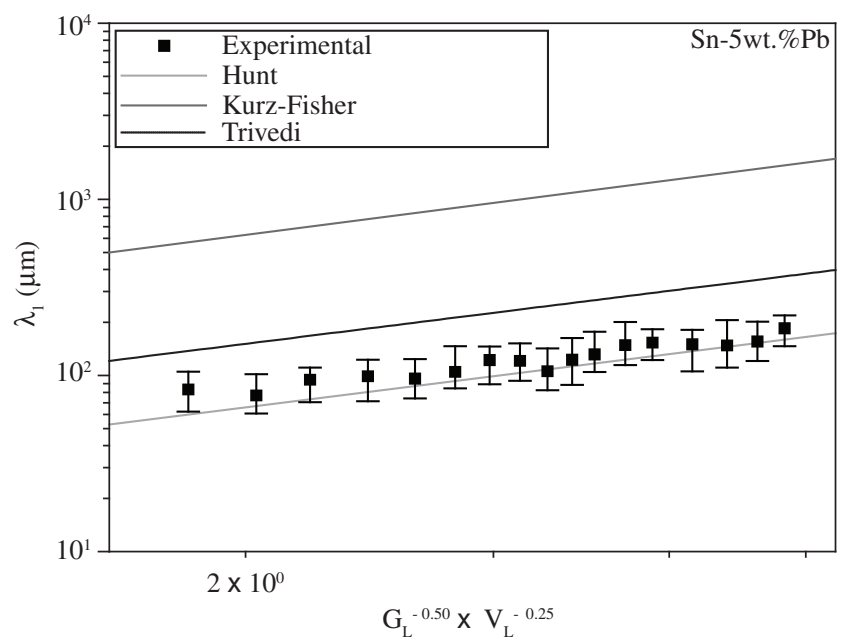

(a)

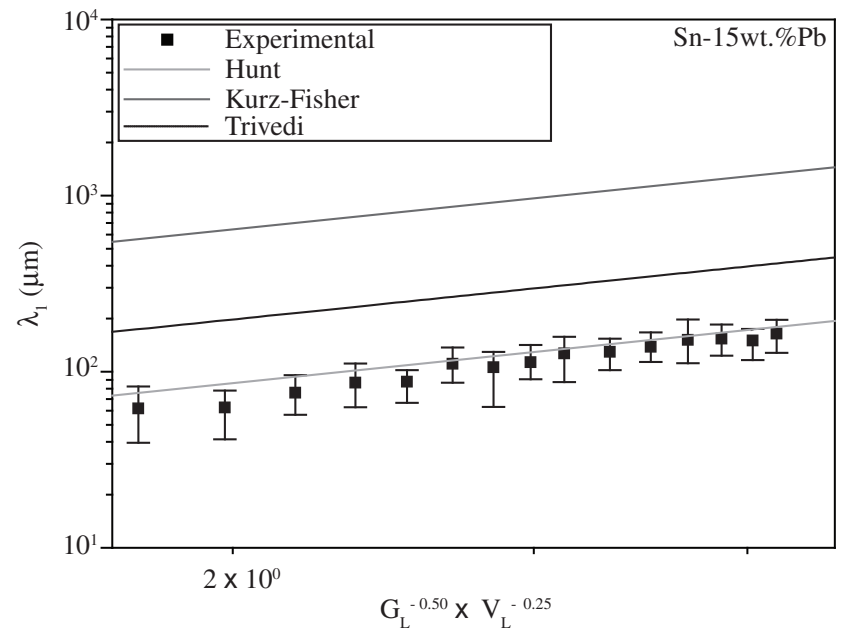

(b)

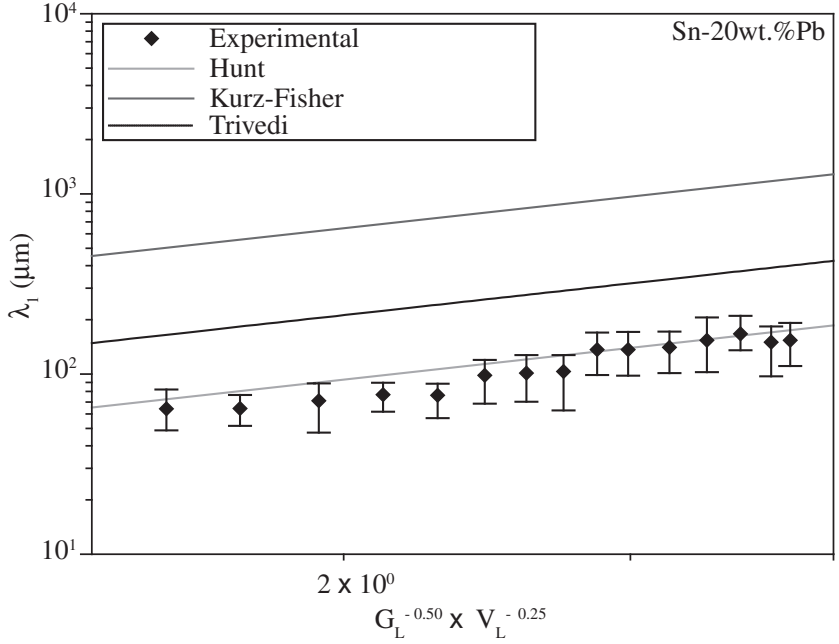

(c)

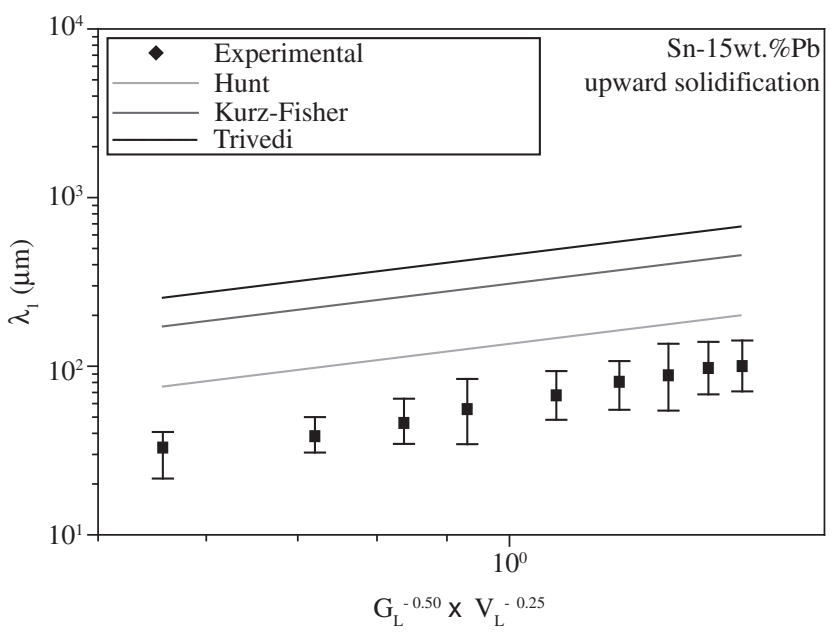

(d)

Figure 5. Comparison of experimental and theoretical (steady-state) primary dendrite arm spacings for Sn-Pb alloys solidified downwards (a, b and c) and upwards (d).

Figure 6 shows comparisons between the present experimental results of secondary dendritic spacings with theoretical predictions furnished by BK's model, given by equation 8 with a calibration factor $\mathrm{a}_{2}$ of 5 for $\mathrm{Sn}-\mathrm{Pb}$ alloys ${ }^{2}$. A good agreement can be observed for any composition examined.

The prediction of Kirkwood's model represented by Equation 9 is compared in Figure 7 with the present $\lambda_{2}$ experimental results. It can be seen that the theoretical predictions generate a slight overestimation of the experimental results for any alloy composition experimentally examined. Concerning the comparison between downward and upward unsteady-state solidification, it can be observed that, for the 5 and $15 \mathrm{wt} . \% \mathrm{~Pb}$ alloys, the upward fit of $\lambda_{2}$ as a function of $\mathrm{t}_{\mathrm{SL}}$ lie between maximum and minimum values of the measured secondary spacings for downward solidification. In fact, a same experimental power law for both upward and downward vertical solidification can be assumed for each alloy composition. It seems that the convection currents induced into the interdendritic region during downward solidification has no significant influence on secondary dendrite arm spacings.

\section{Conclusions}

A comparison between the mean values of $\lambda_{1}$ obtained in the present investigation with those from upward vertical solidification experiments has shown a reduction from 2 to 3 times on primary dendritic spacings for the alloys solidified downwards, demonstrating the strong influence of melt convection on primary dendritic spacings. The secondary dendritic spacings are not affected significantly by the interdendritic convection and a single power law can represent the variation of $\lambda_{2}$ with the tip growth rate in both upward and downward solidification. The unsteady-state $\lambda_{1}$ predictive models (BK and HL) did not generate the experimental observations for both upward and downward unsteady-state solidification systems. 


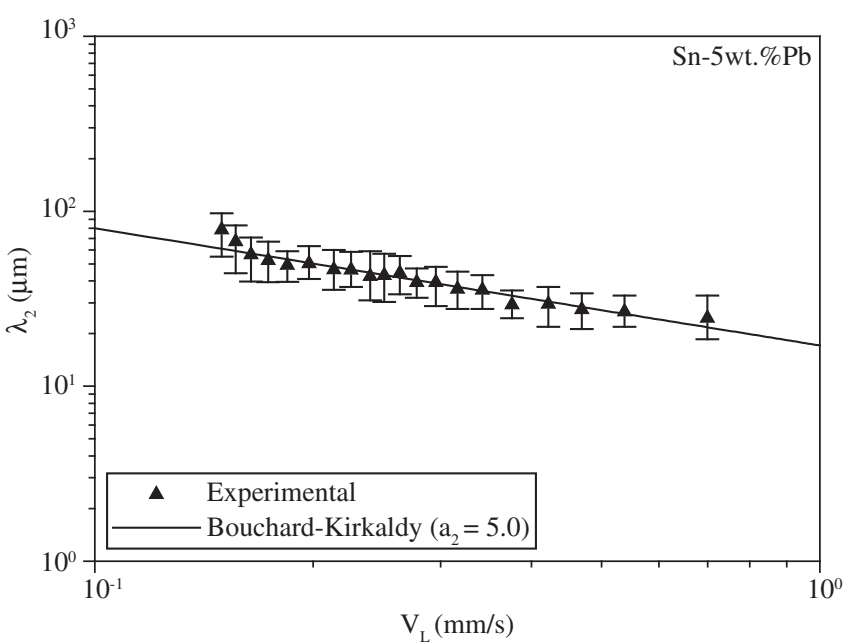

(a)

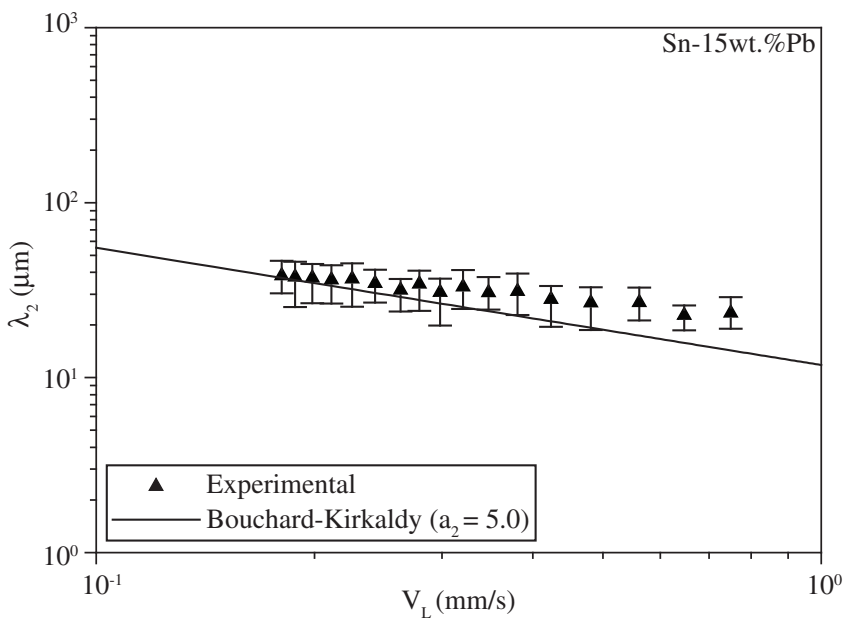

(b)

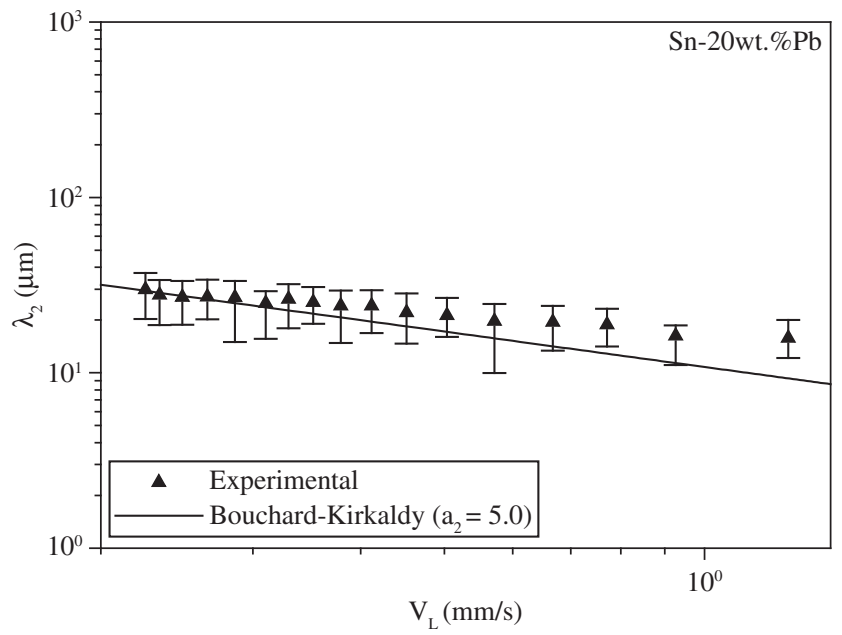

(c)

Figure 6. Comparison of experimental and theoretical secondary dendrite arm spacings as a function of tip growth rate for $\mathrm{Sn}-\mathrm{Pb}$ alloys solidified downwards.

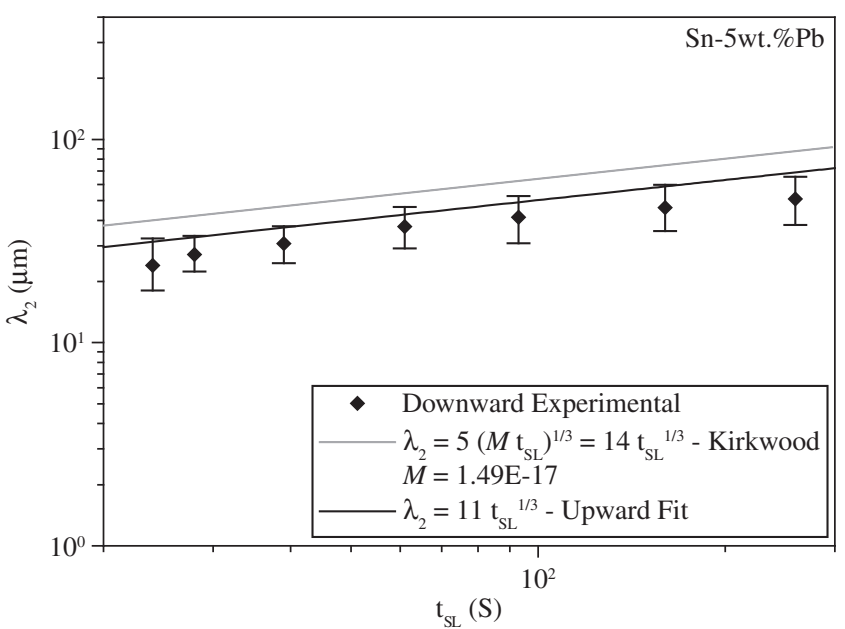

(a)

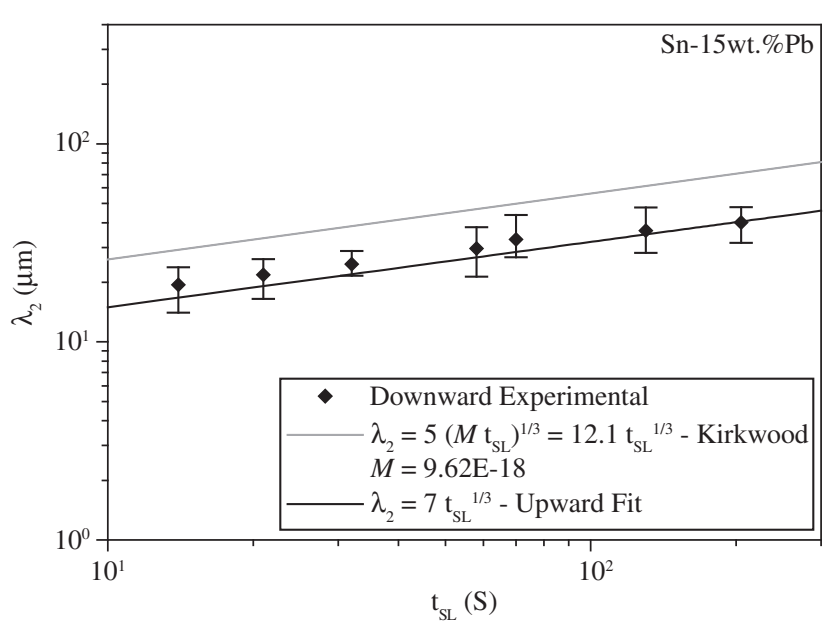

(b)

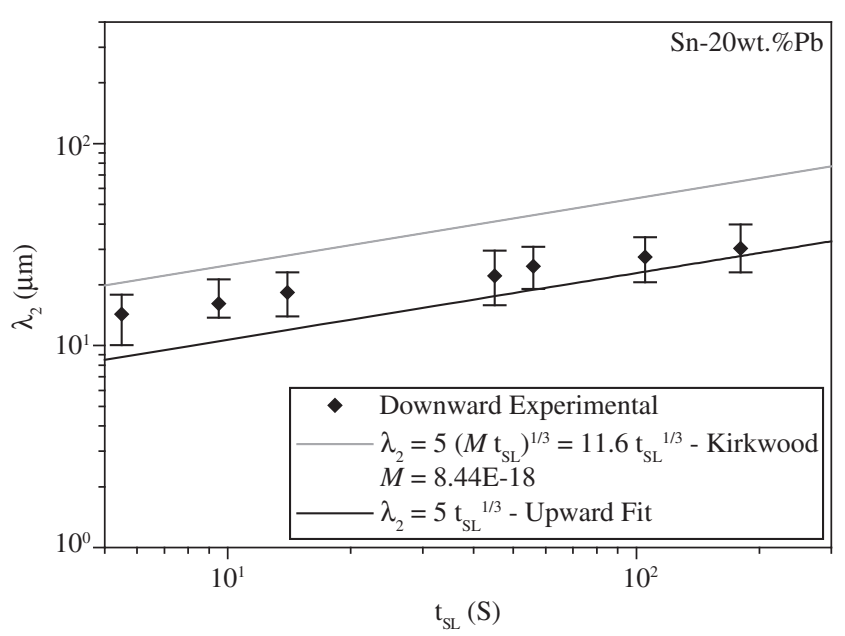

(c)

Figure 7. Comparison of experimental and theoretical secondary dendrite arm spacings as a function of local solidification time $\left(\mathrm{t}_{\mathrm{SL}}\right)$. 


\section{Acknowledgments}

The authors acknowledge financial support provided by FAPESP (The Scientific Research Foundation of the State of São Paulo, Brazil) and CNPq (The Brazilian Research Council).

\section{References}

1. Hunt JD, Lu SZ. Numerical modeling of cellular array growth: Spacing and structure predictions. Metallurgical and Materials Transactions A. 1996; 27:611-623.

2. Bouchard D, Kirkaldy JS. Prediction of dendrite arm spacings in unsteady and steady-state heat flow of unidirectionally solidified binary alloys. Metallurgical and Materials Transactions B. 1997; 28:651-663.

3. Hunt JD. Cellular and primary dendrite spacings. Proceedings of the International Conference on Solidification and Casting of Metals; 1979; London, UK; 1979. p. 3-9.

4. Kurz W, Fisher JD. Dendrite growth at the limit of stability: tip radius and spacing. Acta Metallurgica. 1981; 29:11-20.

5. Kurz W, Fisher JD. Fundamentals of Solidification. Switzerland: Trans Tech Public; 1992.

6. Trivedi R. Interdendritic spacings. A comparison of theory and experiment. Metallurgical and Materials Transactions A. 1984; 15:977-982.

7. Feurer U, Wunderlin R. Appendix 8. In: Kurz W, Fisher D J. Fundamentals of Solidification. Switzerland: Trans Tech Public; 1986.

8. Kirkwood DH. A Simple model for dendrite arm coarsening during solidification. Materials Science and Engineering. 1985; 73:L1-L4.
9. Rocha OL, Siqueira CA, Garcia A. Cellular/dendritic transition during unsteady-state unidirectional solidification of $\mathrm{Sn}-\mathrm{Pb}$ alloys. Materials Science Engineering A. 2003; 347:59-69.

10. Rocha OFL, Siqueira C, Garcia A. Cellular spacings in unsteady-state directionally solidified $\mathrm{Sn}-\mathrm{Pb}$ alloys. Materials Science and Engineering A. 2003; 361:111-118.

11. Rocha OFL, Siqueira CA, Garcia A. Theoretical - Experimental Analysis of Cellular and Primary Dendritic Spacings during Unidirectional Solidification of Sn-Pb Alloys. Materials Research. 2002; 5(3):391-397.

12. Hui J, Tiwari R, Wu X, Tewari SN, Trivedi R. Primary dendrite distribution and disorder during directional solidification of $\mathrm{Pb}-\mathrm{Sb}$ alloys. Metallurgical and Materials Transactions A. 2002; 33:3499-3510.

13. Burden MH, Hunt JD. Some observations on primary dendrite spacings. Metals Science. 1976; p. 156-158.

14. Dupouy MD, Camel D, Favier JJ. Natural convection in directional dendritic solidification of metallic alloys I. Macroscopic effects. Acta Metallurgica. 1989; 37:1143-1157.

15. Li M, Mori T, Iwasaki H. Effect of solute convection on the primary arm spacings of $\mathrm{Pb}-\mathrm{Sn}$ binary alloys during upward directional solidification. Materials Science Engineering A. 1999; 265:217-223.

16. Rocha OL, Siqueira CA, Garcia A. Heat flow parameters affecting dendrite spacings during unsteady state solidification of $\mathrm{Sn}-\mathrm{Pb}$ and $\mathrm{Al}-\mathrm{Cu}$ alloys. Metallurgical and Materials Transactions A. 2003; 34:995-1006.

17. Peres MD, Siqueira CA, Garcia A. Macrostructural and microstructural development in Al-Si alloys directionally solidified under unsteady-state conditions. Journal of Alloys and Compounds. 2004; 381:168-181.

18. Gündüz M, Çardili E. Directional solidification of aluminium-copper alloys. Materials Science and Engineering A. 2002; 327:167-185. 